\title{
Intestinal Absorption of Amino Acids and Peptides in Hartnup Disorder
}

\author{
J. V. LEONARD, T. C. MARRS, J. M. ADDISON, D. BURSTON, K. M. CLEGG, J. K. LLOYD, \\ D. M. MATTHEWS, ${ }^{(35)}$ AND J. W. SEAKINS \\ Institute of Child Health, London, Department of Experimental Chemical Pathology, Vincent Square Laboratories of \\ Westminster Hospital, London, England, and Department of Food Science and Nutrition, University of Strathclyde,
} Glasgow, Scotland

\section{Extract}

This paper reports the investigation of a case of Hartnup disorder, in which tolerance tests were carried out with a mixture of free amino acids simulating casein and a partial enzymic hydrolysate of casein containing small peptides. The investigation also included measurement of renal clearances of amino acids. The patient, a girl aged 26 months, was given by mouth $5 \mathrm{~g}$ amino acid mixture in water, blood samples being taken before the dose and at 15,30 , and $45 \mathrm{~min}$ after the dose. The procedure was repeated with an equivalent dose $(4.7 \mathrm{~g})$ of the enzymic hydrolysate, containing the same amount of nitrogen. The results were compared with those from six normal adults who were given $10 \mathrm{~g}$ amino acid mixture and on another occasion an equivalent dose of an enzymic hydrolysate of casein containing small peptides. In the adults, the increments in the plasma level of a given amino acid were similar whether the amino acid mixture or the enzymic hydrolysate was given. In the patient, a different pattern was seen. In some cases (Lys, Arg, and Pro) there was a large increase in plasma levels after both the amino acid mixture and the enzymic hydrolysate, as in the adult controls. In others (Gly, His, Tyr, Ser, Glu) there was no increase or a decrease in plasma levels after the amino acid mixture, but an increase after the enzymic hydrolysate. In a third category (Ala, Val, Leu, Ile, Met, Phe), increments after the enzymic hydrolysate were greater than after the amino acid mixture. The results with $\mathrm{Thr}$ were unexpected: after the amino acid mixture there was an initial rise in plasma levels and after the enzymic hydrolysate an initial fall. Renal clearances of Pro, Glu, Asp, and Lys were normal and those of Arg and GIn were slightly increased. The clearance of Gly was slightly increased and the clearances of His, Tyr, Ser plus Asn, Ala, Val, Leu, Ile, Met, Phe, and Thr were greatly increased. The results suggest the following. Absorption of free Lys, Arg, and Pro was normal. Absorption of free Gly, His, Tyr, and Ser was probably severely impaired and that of Val, Leu, Ile, Met, and Phe probably subnormal. Absorption of Glu and Ala was probably also subnormal. We cannot account for the results obtained with $\mathrm{Thr}$. The results indicate that many neutral amino acids are malabsorbed in Hartnup disorder, and that free Glu may also be malabsorbed. Amino acids which are poorly absorbed in the free form are better absorbed from peptides. Most of the amino acids with a substantial increase in renal clearance also provided evidence of malabsorption. The finding of an increased renal clearance of Gly agrees with several previous observations in Hartnup disorder.

\section{Speculation}

It is now known that di- and tripeptides are taken up intact by the absorptive cells of the small intestine, in addition to free amino acids. After uptake, the peptides undergo hydrolysis. Previous investigations in Hartnup disorder and cystinuria, combined with physiologic investigations, have shown that mucosal uptake of small peptides is independent of that of amino acids. The present investigation of a case of Hartnup disorder suggests that although many neutral amino acids are poorly absorbed in this condition when given in the free form, absorption of all these "affected" amino acids is better when given in peptide form. It appears that the peptide uptake system or systems of the intestinal mucosa are unaffected by the transport defect of Hartnup disorder, and that this is the explanation of the ability of the patients to maintain a reasonable state of nutrition when on an adequate diet, and of the frequent absence of obvious evidence of intestinal disturbance.

It is now established that in addition to mucosal uptake of free amino acids, there is a second mode of protein absorption in which small peptides are taken up by the absorptive cells, subsequently undergoing intracellular hydrolysis (18). The importance of this mode of absorption in Hartnup disorder, in which there is a congenital transport defect for many neutral amino acids in the small intestine and the kidney $(14,19,20)$, has been suggested by investigations in which the ability of patients to absorb free amino acids and dipeptides have been compared. In the first case to be investigated in this way, it was shown by means of tolerance tests that absorption of free histidine, free tryptophan, and free phenylalanine was grossly impaired, but that absorption of these amino acids from the dipeptides $\beta$-alanylhistidine, glycyltryptophan and phenylalanylphenylalanine was relatively normal $(2,21)$. In a second case, tolerance tests indicated that absorption of free tyrosine was defective, but that this amino acid was well absorbed from glycyltyrosine, and studies of uptake by a jejunal biopsy showed that uptake of free histidine was poor whereas histidine was taken up well from glycylhistidine (26).

In this paper we report the investigation of a third case in which tolerance tests were carried out with a mixture of free amino acids simulating casein, and a partial hydrolysate of casein containing small peptides. After protein meals, the lumen of the small intestine contains a mixture of peptides, probably mainly small peptides, and free amino acids $(1,18)$, so that this procedure appeared to approximate to physiologic conditions more closely than the administration of large doses of individual peptides and of free amino acids. It was hoped that the procedure would provide an indication of how many amino acids were involved in the absorptive defect of this particular patient, and whether all of these or only some were better absorbed from the preparation containing peptides. A preliminary report of this work has appeared (15). The investigation also included measurement of renal clearances of a mino acids.

\section{CASE REPORT}

The patient, $S R$, a girl, the second child of healthy unrelated parents, was born on April 27, 1971. The mother's weight gain during pregnancy was poor and labor started spontaneously after 36 weeks of gestation. It lasted for $6 \mathrm{hr}$ and there were no perinatal 
problems. At birth the patient weighed $1,875 \mathrm{~g}$ and was thought to be both small for dates and premature. Her progress was slow from birth and this was the main presenting feature. At the age of 11 months her developmental age was 4-5 months. Hartnup disorder was diagnosed at 14 months by thin layer chromatography of urine amino acids and the characteristic aminoaciduria involving neutral amino acids demonstrated by the same method on several subsequent occasions. She has never had a rash and the only neurologic sign has been a generalized hypotonia which has slowly improved. On admission to the Hospital for Sick Children, Great Ormond Street, at the age of 26 months, she was well nourished; her height was $85.5 \mathrm{~cm}$ (25th centile) and her weight $10.1 \mathrm{~kg}$ (3rd-10th centile). Her developmental age on the Bayley scales was 8 months. Measurement of the renal amino acid clearances confirmed the diagnosis of Hartnup disorder (see Results and Discussion). All other diagnostic investigations were normal. On discharge from hospital she was started on oral nicotinamide, $50 \mathrm{mg}$ daily. Her general health has subsequently remained satisfactory but developmental delay persists.

\section{MATERIALS AND METHODS}

The amino acid mixture (Table 1) was made up from L-amino acids and glycine from a formula based on the amino acid composition of casein as given by Ling et al. (16). The enzymic hydrolysate of casein, which was readily soluble and intended for oral administration to human subjects, was prepared by hydrolysis with papain followed by further hydrolysis with hog kidney peptidases according to the method described by Clegg et al. $(6,7)$. It contained about $50 \%$ free amino acids and $50 \%$ small peptides of mean chain length estimated to be 2-3 amino acid residues (5).

After an overnight fast from $6 \mathrm{pm}$, at 8 am the patient was given by mouth $5 \mathrm{~g}$ amino acid mixture in $180 \mathrm{ml}$ water. A capillary blood sample was taken immediately before the dose, and further samples taken at 15, 30, and $45 \mathrm{~min}$ after the dose. On the following day at $8 \mathrm{am}$, after an overnight fast from $6 \mathrm{pm}$, the procedure was repeated with an equivalent dose $(4.7 \mathrm{~g})$ of the enzymic hydrolysate, which contained the same amount of nitrogen. After deproteinization with an equal volume of salicylsulfonic acid $(60 \mathrm{~g} /$ liter $)$, plasma amino acids were estimated on a Locarte automatic-loading amino acid analyzer.

It was not possible to obtain control data from normal children, and the results were compared with those from six normal adults, who had been given $10 \mathrm{~g}$ amino acid mixture and on another occasion an equivalent dose $(9.4 \mathrm{~g})$ of an enzymic hydrolysate of casein prepared by a different method, i.e., tryptic hydrolysis (8) but also consisting of a mixture of free amino acids and peptides of 2-3 amino acid residues. The results obtained in normal adults have been fully reported elsewhere (17).

Measurements of renal clearance were based on analysis of a 24-hr urine collection and of a plasma sample obtained during the collection period, before the mid-day meal. Urine and plasma amino acids were estimated on a Technicon TSM amino acid analyzer.

Table 1. Composition of amino acid mixture simulating casein

\begin{tabular}{lccc}
\hline Amino acid & $\mathrm{mmol} / 5 \mathrm{~g}$ dose & Amino acid & $\mathrm{mmol} / 5 \mathrm{~g}$ dose \\
\hline Ala & 1.5 & Lys & 2.4 \\
Arg & 1.0 & Met & 0.9 \\
AspCys & 2.1 & Phe & 1.5 \\
Cys & 0.1 & Pro & 4.6 \\
Glu & 6.9 & Ser & 2.6 \\
Gly & 1.2 & Thr & 1.6 \\
His & 0.8 & Trp & 0.3 \\
Ile & 2.2 & Tyr & 1.2 \\
Leu & 3.4 & Val & 2.7 \\
\hline
\end{tabular}

\section{RESULTS}

The results of the tolerance tests in normal adults showed that at each time interval $(15,30$, and $45 \mathrm{~min})$ the increments in the plasma level of a given amino acid were similar (no significant differences by paired $t$-test) whether the amino acid mixture or the enzymic hydrolysate was given. In the patient, however, a different pattern was seen (Table 2). In some cases (Lys, Arg, and Pro (30)) there was a large increase in plasma levels after both the amino acid mixture and the enzymic hydrolysate, as in the adult controls. (In the case of Pro, 30- and 45-min concentrations were much lower after the enzymic hydrolysate than after the amino acid mixture. This was not seen in the normal adults, but it is possible that it was accounted for by the entry of oligopeptides of Pro into the blood, which is known to occur in man (18). A large number of such peptides, at low concentrations, would not be detected by the analytic procedure used). In others (Gly, His, Tyr, Ser, Glu) there was no increase or a decrease in levels after the amino acid mixture, but an increase after the enzymic hydrolysate. In a third category (Ala, Val, Leu, Ile, Met, Phe) increments after the enzymic hydrolysate were greater than after the amino acid mixture. The results with Thr were quite unexpected: after the amino acid mixture there was a rise in plasma levels at 15 and 30 min followed by a fall at $45 \mathrm{~min}$, but after the enzymic hydrolysate there was a fall at 15 and $30 \mathrm{~min}$ followed by a return at $45 \mathrm{~min}$ to the resting value. These results were confirmed by a repeat analysis.

The results of the renal clearance test are given in Table 3 . The clearances of Pro, Glu, Asp, and Lys were normal, and those of Arg and GIn were slightly increased. The clearance of Gly was slightly increased and the clearances of His, Tyr, Ser plus Asn, Ala, Val, Leu, Ile, Met, Phe, and Thr were greatly increased. In most cases the amino acids with a substantial increase in renal clearance and those apparently involved in the intestinal transport defect (see Discussion) were the same. Exceptions were Glu, which had a normal clearance but was probably malabsorbed when given in the free form, and $T h r$, which had a raised clearance but appeared to be readily absorbed in the free form.

\section{DISCUSSION}

Although "tolerance curves" in peripheral plasma do not ordinarily give a reliable indication of the relative rates of absorption of different substrates from the intestine, being influenced also by renal and tissue clearance of the substrates studied, a special case arises when the same amount of the same amino acid is given $(l)$ in the free form and (2) in peptide-bound form. In these circumstances, mucosal uptake occurs in different forms, but entry into the blood is in the same form (the free amino acid) whether the oral dose is free or peptide bound. This simplifies interpretation of the results. To take a specific example, the failure of the plasma concentration of His to rise after free His in our patients might be contributed to by increased renal and tissue clearance (12), but the large rise in the concentration of this amino acid after the peptide-containing preparation indicates that these factors are unlikely to be entirely responsible, and suggests that malabsorption of the free amino acid plays an important part.

Bearing these considerations in mind, the results suggest the following. Absorption of free Lys, Arg, and Pro was normal. Absorption of free Gly, His, Tyr, and Ser was probably severely impaired, and that of $\mathrm{Val}$, Leu, Ile, Met, and Phe probably subnormal. These results confirm and extend previous observations indicating that a wide range of neutral amino acids (His, Val, Leu, Ile, Met, Phe, Tyr, Trp, Thr) are malabsorbed in Hartnup disorder $(2,12,19,21-23,25,26,29)$, and they support the hypothesis that these amino acids are more satisfactorily absorbed when given in peptide form. It is of particular interest that there was nothing to suggest malabsorption of Pro. This supports the hypothesis (24) that in human intestine and kidney this amino acid is transported largely by a system or systems distinct from the 
Table 2. Resting levels of plasma amino acids and increments in plasma amino acids after patient had ingested amino acid mixture simulating casein and enzymic hydrolysate of casein containing peptides

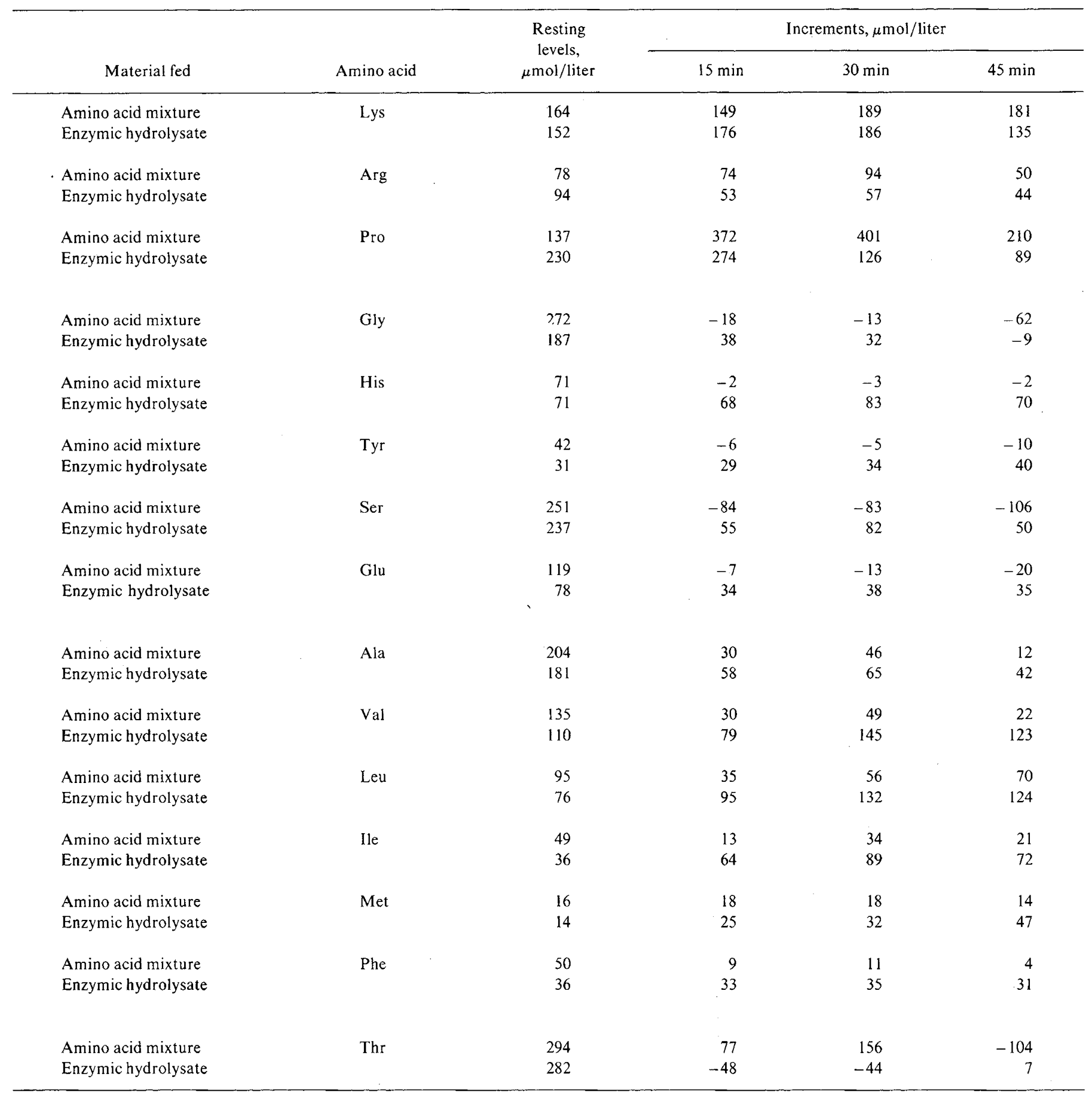

Table 3. Renal clearance of amino acids (milliliters per min $1.73 \mathrm{~m}^{2}$ ) in normal children aged 2-18 years (3) and in patient SR

\begin{tabular}{|c|c|c|c|c|c|}
\hline Amino acid & $\begin{array}{l}\text { Normal values } \\
(\text { mean } \pm S D)\end{array}$ & $\begin{array}{c}\text { Values } \\
\text { in patient }\end{array}$ & Amino acid & $\begin{array}{c}\text { Normal values } \\
(\text { mean } \pm S D)\end{array}$ & $\begin{array}{c}\text { Values } \\
\text { in patient }\end{array}$ \\
\hline Lys & $1.2 \pm 0.4$ & 2 & Val & $0.2 \pm 0.1$ & 41 \\
\hline Pro & 0 & 0 & Ile & $0.3 \pm 0.1$ & 6 \\
\hline Gly & $4.2 \pm 1.4$ & 8 & Met & $0.8 \pm 0.3$ & 8 \\
\hline $\mathrm{His}$ & $9.5 \pm 2.6$ & 86 & Phe & $1.5 \pm 0.3$ & 13 \\
\hline Glu & $0.1-2.4^{1}$ & 2 & Asp & trace $-8.8^{1}$ & 2 \\
\hline Ala & $0.8 \pm 0.4$ & 10 & & & \\
\hline
\end{tabular}

${ }^{1}$ range. 
system or systems utilized by most other neutral amino acids (although shared to some extent by Gly).

Interpretation of the results with Glu and Ala is complicated by the fact that much Glu (whether free or initially peptide bound) (4, 17 ) is transaminated during absorption, yielding Ala, which is absorbed into the blood (28). The results may represent malabsorption of both free Glu and free Ala; however, a possible although unlikely interpretation is that absorption of free Ala was normal, the low curve for Ala following the amino acid mixture actually reflecting only malabsorption of Glu. Although Glu is not involved in the renal transport defect of Hartnup disorder, the possibility that it might share the transport system for neutral amino acids in the small intestine is suggested by the observation that intestinal transport of Glu is strongly inhibited by neutral amino acids in both experimental animals and normal human subjects $(4,10,11,27)$. We are unable to account for the observation that the plasma concentration of Thr initially rises after the amino acid mixture, but initially falls after the enzymic hydrolysate.

The pattern of aminoaciduria in the patient was characteristic of Hartnup disorder, showing a large increase in the excretion of many neutral amino acids, but little or no increase, in the excretion of Pro and the basic and acidic amino acids. The finding of a raised clearance of Gly agrees with several previous observations $(9,25)$, though some authorities, e.g. (14), state that the clearance of Gly is not increased in Hartnup disorder.

\section{SUMMARY}

Absorption of free and peptide-bound amino acids was investigated in a girl with Hartnup disorder aged 26 months. Plasma levels of amino acids were followed after oral administration of $(I)$ an amino acid mixture simulating casein and (2) an equivalent dose of a partial enzymic hydrolysate of casein containing oligopeptides in addition to free amino acids. The results suggested that many neutral amino acids were poorly absorbed when given in the free form, but much more readily absorbed when given as peptides. Unexpectedly, the results also suggested that glutamic acid was poorly absorbed when given in the free form. The results obtained with threonine could not be interpreted. There was an increased renal clearance of many neutral amino acids, including glycine, but clearance of proline was not increased. Most amino acids with an increased renal clearance also appeared to be poorly absorbed when given by mouth in the free form.

\section{REFERENCES AND NOTES}

1. Adibi, S. A., and Mercer, D. W.: Protein digestion in human intestine as reflected in luminal, mucosal and plasma amino acid concentrations after meals. J. Clin. Invest., 52: 1586 (1973).

2. Asatoor, A. M., Cheng, B., Edwards, K. D. G., Lant, A. F., Matthews, D. M., Milne, M. D., Navab, F., and Richards, A. J.: Intestinal absorption of two dipeptides in Hartnup disease. Gut, 11: 380 (1970).

3. Brodehl, J., and Gellissen, K.: Endogenous renal transport of free amino acids in infancy and childhood. Pediatrics, 42: 395 (1968).

4. Burston, D., Addison, J. M., and Matthews, D. M.: Uptake of dipeptides containing basic and acidic amino acids by rat small intestine in vitro. Clin. Sci., 43: 823 (1972).

5. Clegg, K. M.: Unpublished observations.

6. Clegg, K. M., and McMillan, A. D.: Dietary enzymic hydrolysate of protein with reduced bitterness. J. Food Technol., 9: 21 (1974).
7. Clegg, K. M., Smith, G., and Walker, A. L.: Production of an enzymic hydrolysate of casein on a kilogram scale. J. Food Technol., 9: 425 (1974).

8. Crampton, R. F., Gangolli, S. D., Simson, P., and Matthews, D. M.: Rates of absorption by rat intestine of pancreatic hydrolysates of proteins and their corresponding amino acid mixtures. Clin. Sci., 41: 409 (1971).

9. Cusworth, D. C., and Dent, C. E.: Renal clearances of amino acids in normal adults and patients with aminoaciduria. Biochem. J., 74: 550 (1960)

10. Fairclough, P., Silk, D. B. A., Clark, M. L., Marrs, T. C., Burston, D., Clegg, K. Mary, and Matthews, D. M.: To be published.

11. Finch, L. R., and Hird, F. J. R.: The uptake of amino acids by isolated segments of rat intestine. II. A survey of affinity for uptake from rates of uptake and competition for uptake. Biochim. Biophys. Acta, 43: 278 (1960).

12. Halvorsen, S., Hygstedt, O., Jagenburg, R., and Sjaestad, O.: Cellular transport of L-histidine in Hartnup disease. J. Clin. Invest., 48: 1552 (1969).

13. IUPAC-IUB Commission on Biochemical Nomenclature: Symbols for amino acid derivatives and peptides: Recommendations. J. Biol. Chem., 247: 977 (1972).

14. Jepson, J. B.: Hartnup disease. In: J. B. Stanbury, J. B. Wyngaarden, and D. S. Frederickson: The Metabolic Basis of Inherited Disease, 3rd ed., p. 1486 (McGraw-Hill Book Company, New York, 1972).

15. Leonard, J. V., Marrs, T. C., Addison, J. M., Burston, D., Clegg, K. Mary, Lloyd, J. K., Seakins, J. M., and Matthews, D. M.: Absorption of amino acids and peptides in Hartnup disease. Clin. Sci. Molec. Med., 46: 15P (1974).

16. Ling, E. R., Kon, S. K., and Porter, J. W. G.: The composition of milk and the nutritive value of its components. In: S. K. Kon, and A. T. Cowie: Milk: The Mammary Gland and its Secretion, Vol. 2, p. 195 (Academic Press, New York, 1961).

17. Marrs, T. C., Addison, J. M., Burston, D., and Matthews, D. M.: Changes in plasma amino acid concentrations in man after ingestion of an amino acid mixture simulating casein, and a tryptic hydrolysate of casein. Brit. J. Nutr., 34: 259 (1975).

18. Matthews, D. M.: Intestinal absorption of peptides. Physiol. Rev., 55: 537 (1975).

19. Milne, M. D.: Disorders of amino acid transport. Brit. Med. J., 1: 327 (1964).

20. Milne, M. D., and Asatoor, A. M.: Peptide absorption in disorders of amino acid transport. In: D. M. Matthews and J. W. Payne: Peptide Transport in Protein Nutrition, p. 167 (North-Holland Publishing Company, Amsterdam, American Elsevier Publishing Company, New York, 1975).

21. Navab, F., and Asatoor, A. M.: Studies on intestinal absorption of amino acids and a dipeptide in a case of Hartnup disease. Gut, 11: 373 (1970).

22. Pomeroy, J. A. B., Efron, M. L., Dayman, J., and Hoefnagel, D.: Hartnup disorder in a New England family. New Engl. J. Med., 278: 1214 (1968).

23. Scriver, C. R.: A genetic modification of intestinal and renal transport of certain neutral amino acids. N. Engl. J. Med., 273: 530 (1965).

24. Scriver, C. R., and Rosenberg, L. E.: Nature and disorders of imino acid and glycine transport. In: Amino Acid Metabolism and its Disorders, p. 178 (W. B. Saunders, Philadelphia and London, 1973).

25. Shih, V. E., Bixby, E. M., Alpers, D. H., and Bartsocas, C. S.: Studies of intestinal transport defect in Hartnup disease. Gastroenterology, 61: 445 (1971).

26. Tarlow, M. J., Seakins, J. W. T., Lloyd, K. J., Matthews, D. M., Cheng, B., and Thomas, A. J.: Absorption of amino acids and peptides in a child with a variant of Hartnup disease and coexistent coeliac disease. Arch. Dis. Childhood, 47: 798 (1972).

27. Tasaki, I., and Takahishi, N.: Absorption of amino acids from the small intestine of domestic fowl. J. Nutr., 88: 359 (1966).

28. Wiseman, G.: Absorption of protein digestion products. In: D. H. Smyth: Biomembranes, Vol. 4A: Intestinal Absorption, p. 363 (Plenum Press, New York, 1974).

29. Wong, P. W. K., and Pillai, P. M.: Clinical and biochemical observations in two cases of Hartnup disease. Arch. Dis. Childhood, 41: 383 (1966).

30. Standard abbreviations are used for amino acids (13).

31. Informed consent was obtained from the parents.

32. We are grateful to Dr. Barbara Donnison for referring the patient.

33. We are grateful to Mr. J. Milner of Milner Scientific and Medical Research Company Limited for preparation of the amino acid mixture.

34. Dr. D. M. Matthews was supported by a grant from the Medical Research Council of Great Britain.

35. Requests for reprints should be addressed to: Prof. D. M. Matthews, Department of Experimental Chemical Pathology, Vincent Square Laboratories of Westminster Hospital, 124 Vauxhall Bridge Rd., London SWIV 2RH, (England). 36. Accepted for publication November 18, 1975. 